\section{Polyphasisches Schlafmuster}

Helga Peter

Marburg, Deutschland

\section{Englischer Begriff}

polyphasic sleep pattern

\section{Definition}

Bezeichnung für ein $\triangleright$,Schlafmuster“ mit multiplen, über den Tag und die Nacht verteilten Schlafepisoden, wie sie beim Neugeborenen physiologisch sind.

Siehe dazu > „Kindesalter“; >,Schlafdauer“; > ,Einschlafen am Arbeitsplatz“; „Schlafpausen“. 